Albada, A., Elbers, E., Visser, A.

Patient communication in Western European hospitals: a comparison of the Netherlands, Flanders and England.

Patient Education and Counseling: 66, 2007, nr. 1, p. 4-10

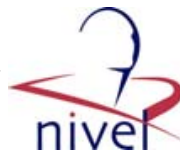

\begin{tabular}{|l|l|}
\hline Postprint Version & 1.0 \\
\hline Journal website & $\underline{\text { http://www.sciencedirect.com/science/journal/07383991 }}$ \\
\hline Pubmed link & $\underline{\underline{h t t p: / / w w w . n c b i . n l m . n i h . g o v / e n t r e z / q u e r y . f c g i ? d b=p u b m e d \& c m d=R e t r i e v e \& d o p ~}}$ \\
\hline t=AbstractPlus\&list_uids=17317079\&query_hl=1\&itool=pubmed_docsum
\end{tabular}

\title{
Patient education in Western European hospitals: A comparison of the Netherlands, Flanders and Englanda
}

\author{
AKKE ALBADA $^{\text {A* }}$, ED ELBERS ${ }^{\mathrm{B}}$, ADRIAAN VISSER $^{\mathrm{C}}$ \\ ${ }^{a}$ NIVEL, Netherlands Institute for Health Services Research, The Netherlands \\ ${ }^{b}$ Langeveld Institute for Pedagogical and Educational Research, Faculty of Social Sciences, Utrecht \\ University, The Netherlands \\ ${ }^{\mathrm{C}}$ Helen Dowling Institute, Center for Psycho-social Oncology, The Netherlands \\ *Corresponding author. Tel.: +31 302729 638. E-mail address: a.albada@nivel.nl (A. Albada). \\ aThe research reported in this article was carried out as part of the first author's master thesis in \\ interdisciplinary social science at Utrecht University.
}

\begin{abstract}
Objective: This research describes the organization of patient education in hospitals and the conditions that influence this in the Netherlands, Flanders and England.

Methods: The research consists of document analysis and interviews.

Results: On the organizational level, there can be a patient information desk (England and the Netherlands) and/or a specialized officer on patient education (the Netherlands and England). In the three countries/regions, the organization of patient education on the program level, for patient groups, is characterized by consultations of specialized nurses, patient information materials and patient education policy. Expert centers stimulate patient education through training and quality projects. Lobbying by patient organizations is important for the setting up of patient education. Both expert centers and patient organizations are financially dependent on and respond to policy of the government.

Conclusion: Patient education is mostly organized on the organizational level or the program level, or both. Patient organizations and expert centers are conditions that are dependent on the government. Government policy and subsidies are considered as the most important conditions for the organization of patient education in hospitals.

Practice implications: Commitment of officers working in patient education to the Health Promoting Hospital project and the European Association for Communication in Healthcare could stimulate patient education.
\end{abstract}

\section{INTRODUCTION}

There are huge differences between national health systems within the EU [1]. One important difference is that British hospitals are government organizations run by the National Health Service (NHS). Hospitals in the Netherlands and Belgium are private organizations subject to national legislation. Government cannot directly steer these private hospitals through policy [2]. In Flanders, there is little policy in healthcare [3]. In England and the Netherlands, there is more government policy on hospital matters. These differences between healthcare systems are likely to influence the organization of patient education. 
Albada, A., Elbers, E., Visser, A.

Patient communication in Western European hospitals: a comparison of the Netherlands, Flanders and

England.

Patient Education and Counseling: 66, 2007, nr. 1, p. 4-10

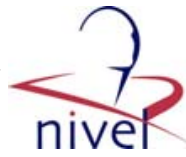

Comparative research into general practice has shown differences between European countries in patient expectations and patient evaluations of doctor-patient communication [4]. There is no international comparative research on patient communication in hospitals. In general, there are many studies on the effectiveness of patient communication, but little is known about the current organization of patient communication. There is scarce evidence of which conditions at national level can stimulate patient education [5]. This is why, the organization of patient education within Western European countries was chosen as the subject for this present research.

Patient education can be organized at national level, for instance, by developing websites that provide patient information. It can also be a responsibility for every hospital, which is referred to as the hospital or organizational level of patient education. And patient education can also be organized for specific patient groups, such as programs for diabetics or breast cancer patients. This is called the program level of organization of patient education. And finally, patient education can be the responsibility of the individual healthcare worker. Fig. 1 shows the conditions that can influence the organization of patient education on each level.

\section{[ FIGURE 1 ]}

In this study, we looked for differences in the organization of patient education in hospitals and at the conditions that influenced this. Three English or Dutch speaking EU countries/regions were selected: the Netherlands, Flanders and England. Because of differences in regional governments, in Great Britain only England was included in the study, and Flanders in Belgium.

The research questions are:

(1) How is patient education organized at the organizational and program levels in hospitals in the Netherlands, Flanders and England?

(2) What are the conditions that influence the organization of patient education in hospitals in the Netherlands, Flanders and England?

Patient education is defined by Van den Borne as: 'a systematic learning experience in which a combination of methods is generally used, such as the provision of information and advice and behavior modification techniques, which influence the way the patient experiences his illness and/or his knowledge and health behavior, aimed at improving or maintaining health or learning to cope with a condition, usually a chronic one' [6]. Patient education is therefore an element of patient communication and health communication and an integral part of the healthcare process.

\section{METHODS}

Two methods were used: document analysis and interviews.

\subsection{Document analysis}

The document analysis was performed in 2004, and focused on books, congress papers, articles and websites. The documents were selected using Omega online contents, catalogues from Utrecht University (UU), Netherlands Institute for Health Services Research (NIVEL), Netherlands Institute for Health Promotion and Disease Prevention (NIGZ) and an online Google search of the internet. The catalogues from the UU, NIGZ and NIVEL were searched for the words: patient education, patient communication, healthcare communication, patient compliance, informed consent, shared decision making, healthcare Europe, healthcare system and patient rights. These words were searched for in English and a Dutch translation. Eighty English and 56 Dutch documents were selected. Omega online contents were searched for the words: patient education, patient communication and healthcare communication in combination with the region/country names: the Netherlands, Flanders/Belgium, England/Great Britain/United Kingdom. After the names and/or abstracts of articles had been screened, five relevant articles were found. Google was used to search the internet for the combination of the words: patient education/ patient communication, organization and hospital, in English and Dutch translation. The first 50 pages of every search were screened and a total of 24 websites were selected.

The contents of the selected documents and websites were screened for information on the levels of organization of patient education and the conditions for this—as set out in Fig. 1. Examples of these 
Albada, A., Elbers, E., Visser, A.

Patient communication in Western European hospitals: a comparison of the Netherlands, Flanders and

England.

Patient Education and Counseling: 66, 2007, nr. 1, p. 4-10

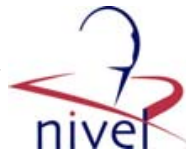

conditions are policy on and subsidies for patient education, patient rights on information and consent, guidelines on patient education and the presence of officers or nurses tasked with organizing patient education in hospitals. Policy can be that of hospitals, governments, patient organizations, expert centers, health insurance companies, professional organizations for healthcare workers or NGOs relevant for communication in the healthcare sector. After screening, 95 documents and 24 websites remained. Relevant information found in these documents is described in Section 3 and literature references are given.

\subsection{Interviews}

In each country/region, five interviews were held in the period between November 2004 and May 2005. Depending on the characteristics of the country/region, these interviews were conducted with an officer responsible for all or some of the organization of patient education on the organizational level in a hospital, a policy officer from a patient organization, a policy officer from an expert center, a department executive of a health insurance company, a national government ombudsman and a committee member of a professional organization in patient education. Not every officer mentioned was consulted in all three countries/ regions because of the differences in the healthcare systems. For instance, there are no health insurance companies in England and in Flanders there is no expert center on patient education. In the interviews, the description of how patient education is organized according to the document analysis was verified and the situation in that particular country was further elaborated upon. The interview questions focused on the conditions for the organization of patient education that the respondent knew most about, for instance, the policy of an expert center or national patient rights. The interviews in hospitals also focused on the types of patient education offered to diabetes, stroke and cataract patients.

The interviews were transcribed and analyzed by coding text fragments. The codes can be used to compare fragments on one subject from different interviews. The main codes were the levels of the organization of patient communication given in Fig. 1: international level, national level, organizational level, program level. Each main code had subcodes, which are the conditions listed in Fig. 1. Subcodes for the main code of national level are, for instance, government policy and the policy of expert centers. The outcomes of the document analysis and the interviews confirmed each other. The additional value of the interviews was the information gained about the organization of patient education in practice, recent policy developments and about the impact of differences in the national health systems on the organization of patient education.

\section{RESULTS}

The countries differ in the level(s) on which patient education is organized. There are differences on the organizational level in the presence or absence of patient education officers and patient information desks, and on program level on the presence or absence of specialized nurses, patient information materials and guidelines on patient education for specific patient groups. These and other

differences in the organization of patient education will be presented. The conditions that influence the organization of hospital-related patient education that were found in the documents and/or mentioned by respondents are described. Little information was found on policy on patient education among professional organizations for doctors, nurses and paramedics. Therefore, this could not be described as a condition. The most important conditions found in this research are the national government, patients organizations and expert centers.

\subsection{The Netherlands}

The Dutch government initiated the employment of patient education coordinators in hospitals in the 1980s. After a pilot project, almost all hospitals employed a patient education coordinator [7]. These officers work at the organizational level of patient education and are now generally called patient communications officers. The patient communications officers are organized within a professional organization, the Association for Patient Education and Counseling (Vereniging PatiëntenVoorlichting, VPV) [8]. The most common functions are those of patient communications advisor and patient communications officer [9]. Patient communications advisors work in quality projects on patient communication, advise healthcare workers and edit patient education materials. The patient communications advisor is usually the executive of a patient information desk. More than 
Albada, A., Elbers, E., Visser, A.

Patient communication in Western European hospitals: a comparison of the Netherlands, Flanders and

England.

Patient Education and Counseling: 66, 2007, nr. 1, p. 4-10

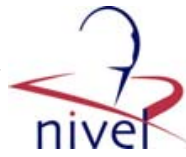

half of the Dutch hospitals have a patient information desk. The patient communications officers working at the desks give complementary information to patients and visitors and register patient's complaints about the hospital. More than half the hospitals have a network of nurses with special tasks in patient education, referred to as contact persons (COPA) networks [8]. The patient communications officers, the COPA networks and the patient information desks together form the organizational level of patient education.

On the national level, it is the expert center on patient communication, the law on patients' rights and patient organizations that stimulate conditions for patient communication. The Dutch Institute for Health Promotion and Disease Prevention (NIGZ), established in 1980, is the expert center on patient communication. It is a government initiative and the government still structurally subsidizes a third of the budget. The NIGZ trains healthcare workers and patient communications officers, and is a partner in quality projects on patient communication [10]. As of 1995, the Medical Treatment Contract Act (WGBO) has made it the duty of healthcare workers to provide their patients with information [1113]. This law greatly stimulated the policy and practice of patient education in hospitals and heralded the start of a broad implementation program that focused on informed consent. This program stimulated patient education because patients need to be informed to be able to give their consent. Tools such as communication protocols for doctors and reminders for patients were developed. The patient organizations were reorganized by the government in the 1990s into a National Platform, the Dutch Patients/ Consumers Federation (NPCF) [14]. This patient organization has a stimulating influence on the organization of patient education through lobbying and quality projects in health care [15].

In Dutch hospitals on the program level of patient education, there are specialized nurses with important roles in patient education for several patient groups. Dutch hospitals have a large number of patient leaflets on treatments that are developed within the hospital. Policy on face-to-face education is present in Dutch hospitals for some patient groups and is developed in multidisciplinary projects supported by a patient communications officer [8]. In the case of the Amphia Hospital in Breda/Oosterhout, consulted in this research on patient education for diabetes, stroke and cataract patients, there are specialized nurses for diabetes and stroke patients. Information leaflets are also available for these patients. A guideline on the timing of face-to-face and written information by healthcare workers is present for stroke and cataract patients. The organization of patient education on the program level consists therefore of patient leaflets for almost every patient group and specialized nurses or multidisciplinary education protocols for some patient groups.

\subsection{Flanders}

Most Flemish hospitals have little organization of patient education on the organizational level. The editing of patient information leaflets is an important activity on the organizational level. This task is generally among the responsibilities of a general communications officer. Some hospitals have quality projects in patient education. However, through a lack of national or regional policy there is no coherence in these initiatives [16]. The Saint Vincentius Hospital in Antwerp, part of the GuestHouse Sisters of Antwerp (GVA) group, has a network of contact persons for patient education. The communications officer is a central person within this network. The coordination of the network, editing patient leaflets and coordinating quality projects in patient education are among the responsibilities of the communications officer. Until recently these were the tasks of a patient education coordinator, but this function no longer exists. We found no other Flemish hospitals that had experience with a specialist patient communications officer. Neither did we find any Flemish hospital with an information desk for patients. An ombuds service is present in every hospital, but this is a service for complaints and not for patients' requests for information. The organizational level of patient education therefore mostly consists of the development of patient leaflets by a general communications officer.

Flanders has a lack of a healthcare policy, the main reason for which is the existence of a Federal and a Flemish government [3]. Cooperation between different governments is an obstacle for the development of policy. In 2002, the Law on Patient's Rights stipulated that every hospital should have an ombuds service [17]. The ombuds services have now been implemented in hospitals. The law also set out guidelines for patient education but these guidelines do not greatly influence practice. No implementation programs were started pursuant to the law on patient education, such as informed 
Albada, A., Elbers, E., Visser, A.

Patient communication in Western European hospitals: a comparison of the Netherlands, Flanders and

England.

Patient Education and Counseling: 66, 2007, nr. 1, p. 4-10

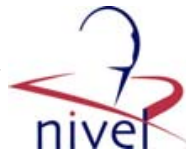

consent. One of the possible explanations for this might be the large amount of professional freedom enjoyed by Belgian doctors. Flanders has no expert center on patient education. Patient organizations lack influence both on the healthcare policy of the government and on hospital policy, due to a lack of funding. The health insurance companies have an important role in the defense of patients' interests, which may sometimes conflict with other aims of the organization. There is no exchange between Walloon (the French speaking part of Belgium) organizations for patient education and Flemish hospitals. Although Wallonia has an expert center on patient education, a professional organization for nurses in patient education and a Health Promoting Hospital (HPH) network [16], Flemish hospitals do not benefit from these organizations. Explanations for this gap are the language differences (Dutch in Flanders as opposed to French in Wallonia) and the different regional governments and health policy for Flanders and Wallonia. The most important conditions for patient education on a national level in Flanders are therefore the health insurance companies and the government.

The Saint Vincentius Hospital, consulted in this research, has specialized nurses for various patient groups, such as diabetes. These nurses play an important role in patient education for this particular patient group. The hospital developed patient education leaflets for diabetes and cataract patients. Policy on when to give face-to-face information and leaflets is present for education with diabetes patients. On the program level, patient education therefore mostly consists of patient leaflets and for some patient groups there is a specialized nurse.

\subsection{England}

The British organization of patient education has undergone considerable development in the past 10 years due to changing government policy. The 2000 NHS plan describes the start of a Patient Advice and Liaison Service (PALS) on the organizational level of each hospital. The first aim of the PALS is to handle and solve patients' complaints [18]. The PALS also receives requests for information and is able to give information on hospital services and offer guidance on how to access other health information. Some English hospitals have initiatives in the organization of patient education, but except for the PALS, these initiatives are not standard and not supported by national policy [19]. Some hospitals employ a patient literature officer. One of these hospitals is King's College Hospital in London. These officers edit patient information leaflets. They are not involved in the quality of faceto-face patient education. The organizational level of patient education in English hospitals consists of a PALS and in some hospitals a patient literature officer.

Organizations on the national level of patient education mainly focus on written patient information. The Health Department and the hospital insurance company of the NHS (the Clinical Negligence Scheme for Trusts), both have norms for the subjects that need to be covered in (hospital) patient information leaflets. In 1997, an expert center for health information was funded-the Center for Health Information Quality (CHIQ). The center has a quality hallmark for health information - mainly in the form of websites and leaflets - that focuses on readability of the text. The CHIQ also has a coordinating function in the training of PALS officers [20]. The future of this center is uncertain because of a lack of government funding. There are several national patient organizations, without a clear structure and with a lack of funding and political influence [21,22]. There are some projects on patient education in the Health Promoting Hospitals network in England. In 1991, the Patients' Charter was developed as a policy document on patients' rights [22]. This document has no legal status, and therefore no individual rights can be derived from the charter [23]. In 2001, a new political program substituted this policy document: 'Your guide to the NHS'. This document too has no legal status, but sets out the minimum service the NHS should deliver to patients [24]. The guide outlines sketchy norms on patient education. English law however does prescribe informed consent [25]. On the national level of hospital patient education, the Health Department, the NHS hospital insurance company and the CHIQ expert center are important conditions.

On the program level of patient education there are several specialized nurses for patient groups, such as diabetes and stroke. The King's College hospital has information leaflets available for some patient groups, for instance cataract patients. There is no policy on face-to-face patient education. Patient education on the program level therefore consists of patient leaflets and specialized nurses with an important role in patient education for some patient groups. 
Albada, A., Elbers, E., Visser, A.

Patient communication in Western European hospitals: a comparison of the Netherlands, Flanders and England.

Patient Education and Counseling: 66, 2007, nr. 1, p. 4-10

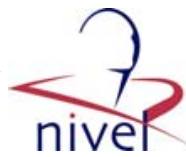

\subsection{Influence of the European organizations and the WHO}

Healthcare systems are a national concern within the European Union (EU). As a result, the EU as such has little policy on health care. The little policy that the EU did develop focuses on e-health and on collaboration between member states in matters relating to care for the elderly and health care [26,27]. In this research, no influence of this policy on the organization of patient education was found.

The World Health Organization (WHO) stimulates patient education through the Health Promoting Hospitals project [28,29]. As opposed to English hospital trusts, Flemish and Dutch hospitals are not connected to the HPH network [30,19]. The HPH networks advise (European) governments [16]. The financing of projects within the HPH project comes partly from EU sources. Health promotion projects aimed at patients and their relatives can encourage healthy behavior of patients and effective support from relatives. Examples of projects are interventions for smoking cessation and counseling on diet and physical training [31]. The range of subjects of HPH projects is broad and patient education projects are only a small part of $\mathrm{HPH}$. The HPH is, however, important for including patient education in an integral vision on health promotion in hospitals [32].

There are various Non-Governmental Organizations (NGOs) on the European level, such as European patient organizations, professional organizations of healthcare workers and an organization for European hospitals. The goals of these organizations are mostly knowledge transfer and lobbying at European level. Most European NGOs focus on abstract themes and have no influence on the organization of patient education. The European Association for Communication in Healthcare (EACH) aims to stimulate research and education on communication in health care [33] and especially the reciprocity between these two [34]. A European organization with influence on the practice of patient education is the European Association for the Study of Diabetes (DESG) for healthcare workers in diabetes, which gives advice and best practice on patient education in diabetes [35].

\section{DISCUSSION AND CONCLUSION}

\subsection{Discussion}

There is little research on the organization of patient education in hospitals. In 2000, Patient Education and Counseling published a couple of articles on the organization of patient education in European countries $[14,17,25]$. The perspectives from which these articles are written vary. The research examined in this present article gives a description of the organization of patient education within hospitals from an organizational perspective and gives an insight into the conditions influencing it. The organization of patient education in the various countries is difficult to compare because of the huge differences in the healthcare systems. The impact of the organization of patient education on the practice of doctor-patient communication is not clear. As a result, this study can say nothing about quality differences in the practice of doctor-patient communication.

Although the results of the document analysis and the interviews confirmed each other, an amount of five interviews is insufficient to give a good description of patient education in all hospitals in a country or region and the relevant conditions. The selected hospitals in which a patient education officer was interviewed are cases only. They may differ from other hospitals in a country/region. Also the description of the situation in the three countries/ regions might not be recent and accurate on all aspects, due to sometimes rapid changes in health policy and the limited scale of the document analysis. However, this research does give a broad view on the organization of patient education within Western European hospitals. Better and more extensive research is needed to describe the organization of patient education and analyze exactly which conditions are important for this.

\subsection{Conclusion}

In all three countries/regions, the Netherlands, England and Flanders, there is patient education on the organizational level and on the program level. The organizational level is strongest in the Netherlands through the employment of patient communications officers in hospitals. Both the Netherlands and England have information desks in hospitals. Compared with the Netherlands and England, patient education on the organizational level is the least organized in Flanders. The organization of patient education on the program level, mainly through patient information leaflets and specialized nurses, is quite similar in the three countries/regions. 
Albada, A., Elbers, E., Visser, A.

Patient communication in Western European hospitals: a comparison of the Netherlands, Flanders and England.

Patient Education and Counseling: 66, 2007, nr. 1, p. 4-10

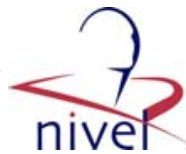

Policy on patient education of expert centers and of patient organizations is an important condition for the organization of patient education in hospitals. In England, the CHIQ expert center has stimulated the quality of health information, but is currently struggling through a lack of subsidies. In Flanders, there is no expert center for patient communication. In the Netherlands, the NIGZ expert center supports a quality improvement of patient communication, the institute is (partly) structurally financed by the government. Dutch patient organizations have triggered hospitals to pay more attention to patient education. Patient organizations were facilitated in this by financial and policy support from the national government. Patient organizations in both England and Flanders lack weight and influence because of a lack of funding. Political pressure to improve patient education is therefore not possible.

Governmental policy and subsidies are the most important conditions in the organization of patient education. Through the policy on patient participation and patient education, the national government lays the foundation for the structure and financial situation of the patient organizations and expert centers. By policy on and the subsidizing of patient organizations, the government determines whether patient organizations can fulfill their stimulating role and lobby for the sake of patient education. Expert centers stimulate patient education through quality projects and training. Supporting government policy is therefore a prerequisite for a stimulating role of expert centers and patient organizations in patient education. This research suggests that where there is a stable organization of patient education in hospitals, it is mainly the result of governmental policy and subsidy.

\subsection{Practice implications}

From an integrated vision on health promotion within hospitals, the HPH project has a stimulating role on patient education. The HPH network can be seen as an opportunity for the further integration of patient education in the hospital organization. This can break the tendency to see patient education as simply handing the patient an information leaflet. Patient education should be an integrated part of the patient pathway. Also health promotion activities should be linked with continuous quality improvement programmes and principles of health promotion are to be incorporated into the organizational structure and culture [30]. Hospitals, especially in the Netherlands and Flanders, should therefore rethink the option to commit to the HPH network. Officers working on (the organizational level of) patient education should lobby in their organizations for this commitment.

The European Association for Communication in Healthcare is committed to research and practice [33]. Respondents in this study were not aware of the organization. However, more membership of officers working on the organizational level of patient education might stimulate evidence-based patient education within hospitals and guarantee research attention for the organizational prerequisites for good health communication.

\section{FIGURE}

\begin{tabular}{|c|c|}
\hline Level & Conditions \\
\hline International level & EU programs, policy of NGOs \\
\hline National level & $\begin{array}{c}\text { Patient rights, government policy, } \\
\text { government subsidy, policy of } \\
\text { patient organizations, policy of } \\
\text { expert centers }\end{array}$ \\
\hline Hospital/organizational level & $\begin{array}{c}\text { Hospital policy, patient education } \\
\text { officers, information desk }\end{array}$ \\
\hline Program level & $\begin{array}{c}\text { Guidelines, education guidelines, } \\
\text { patient leaflets, specialized nurses }\end{array}$ \\
\hline
\end{tabular}

Fig. 1. Levels of responsibility for patient education.

\section{REFERENCES}

1. Collaris JWM, Bakker WE. Naar een Europese gezondheidszorg? (Towards a European healthcare) In: Engelbersen G, Hemerijk AC, Bakker WE, editors. Zorgen in het Europese 
Albada, A., Elbers, E., Visser, A.

Patient communication in Western European hospitals: a comparison of the Netherlands, Flanders and England.

Patient Education and Counseling: 66, 2007, nr. 1, p. 4-10

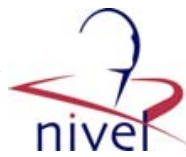

huis, verkenningen over de grenzen van de nationale verzorgingsstaten. Amsterdam: Uitgeverij Boom; 1994.

2. Kümpers S, Van Raak A, Hardy B, Mur I. The influence of institutions and culture on health policies: different approaches to integrated care in England and the Netherlands. Public Adm 2002;80: 339-58.

3. European Observatory on Health Care Systems. Health care systems in transition: Belgium. Copenhagen: European Observatory on Health Care Systems; 2000.

4. Van den Brink-Muinen A, Bensing JM, Verhaak PFM. The eurocommunication study: an international comparative study in six European countries on doctor-patient communication in general practice. Utrecht: NIVEL; 1999.

5. Visser A. Patiëntenvoorlichting in Europa (Patient education in Europe). Intermezzo 2002;1:911.

6. Van den Borne B. The patient from receiver of information to informed decision-maker. Patient Educ Couns 1998;34:89-102.

7. De Boer M, Gaasbeek I, Noorlander J. Handboek coördinator patiëntenvoorlichting (Handbook co-ordinator patient education). Woerden: Landelijk Centrum GVO; 1995.

8. Albada A. Patiëntenvoorlichting onder de loep een inventariserend onderzoek naar de stand van zaken van patiëntenvoorlichting anno 2002 (Patient education scrutinized). Woerden: Vereniging PatiëntenVoorlichting (VPV); 2003.

9. Van Bennekom J. Patiëntenvoorlichting of patiëntencommunicatie (Patient education or patient communication?) What's in a name?. Leiden: Nederlands Instituut voor Postacademisch Onderwijs; 2001.

10. www.nigz.nl.

11. Kastelein WR. Patiëntenwetgeving: bureaucratie of bescherming? (Patient laws: bureaucracy or protection?) Toetsing van (evaluatie van) wetgeving. Lelystad: Koninklijke Vermande; 2002.

12. Leenen HJJ. Handboek gezondheidsrecht (Handbook health rights) deel 2 gezondheidszorg en recht. Houten: Bohn Stafleu Van loghum; 2002.

13. Exter A, Hermans H, Dosljak M, Busse R. Health care systems in transition: Netherlands. Copenhagen: WHO Regional Office for Europe on behalf of the European Observatory on Health Care Systems; 2004.

14. Consumentenbond. Consumentengids patiëntenrecht (Consumer guide on patient rights). Utrecht: Kosmos; 1998.

15. Bensing JM, Visser A, Saan H. Patient education in the Netherlands. Patient Educ Couns 2001;44:5-22.

16. Deccache A, Van Ballekom K. Patient education in Belgium: evolution, policy and perspectives. Patient Educ Couns 2001;44:43-8.

17. Vansweevelt T. Patiëntenrechten in België; gelijkenissen en verschilpunten met Nederland (Patients' rights in Belgium). Tijdschr Gezondheidsrecht 2004;28:91-108.

18. Grant S. How the face of shaping healthcare has changed. The way ahead Commission for patient and public involvement in health 2004;4-9.

19. Skelton A. Evolution not revolution? The struggle for the recognition and development of patient education in the UK. Patient Educ Couns 2001;44:23-7.

20. www.chiq.org.uk.

21. Wilson J. Acknowledging the expertise of patients and their organizations. BMJ 1999;18:7714.

22. European Observatory on Health Care Systems. Health care systems in transition: United Kingdom. Copenhagen: European Observatory on Health Care Systems; 2000.

23. Coulter A, Magee H. The European patient of the future. Maidenhead: Open University Press; 2003.

24. Gevers S. The right to health care. Eur J Health Law 2004;11:29-34.

25. Leenen HJJ, Gevers JKM, Pinet G. The rights of patients in Europe, a comparative study. Deventer: Published on behalf of the WHO regional office for Europe, Kluwer; 1993.

26. European Commission. E-Health, making healthcare better for European citizens: an action plan for a European e-health area. Brussels: European Commission; 2004 [SEC(2004)539].

27. Social Agenda. Facing common health care challenges, new commission proposals call for more co-operation between member states. Social Agenda. European commission employment and social affairs; 2004.

28. www.who-cc.dk.

29. www.hph-hc.cc. 
Albada, A., Elbers, E., Visser, A.

Patient communication in Western European hospitals: a comparison of the Netherlands, Flanders and England.

Patient Education and Counseling: 66, 2007, nr. 1, p. 4-10

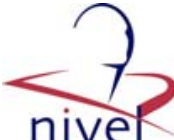

30. WHO. Standards for Health Promotion in Hospitals. Copenhagen: WHO Regional Office for Europe; 2003.

31. Groene O, Garcia-Barbero M. Health promotion in hospitals: evidence and quality management. Copenhagen: WHO Regional Office for Europe; 2005.

32. Gröne O. Evolution and directions for the International Network of Health Promoting Hospitals. In: 11th International conference on health promoting hospitals, re-orientating hospitals towards better health in Europe; 2003.

33. www.each.nl.

34. Van Dulmen S, Finset A, Langewitz W, Zimmermann C, Peltenburg M, Visser A, Bensing J. Five years of EACH (European Association for Communication in Healthcare). Patient Educ Couns 2006;62: 379-84.

35. www.desg.org. 